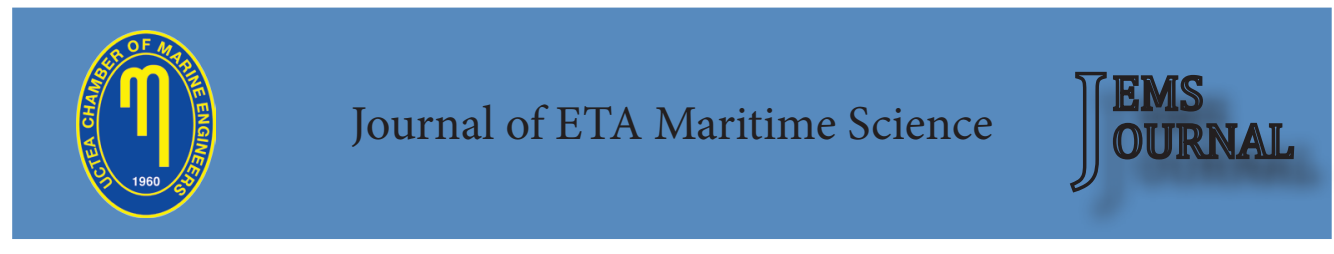

\title{
After Meeting
}

\section{The $1^{\text {st }}$ Maritime Pilotage/Towage Services and Technologies Congress}

\section{Adnan PARLAK}

Ylldız Technical University, Faculty of Naval Architecture and Maritime, adnanpar@gmail.com

The $1^{\text {st }}$ Maritime Pilotage/Towage Services and Technologies Congress has been organized by UCTEA Chambers of Marine Engineers, UCTEA the Chamber of Turkish Naval Architects \& Marine Engineers and Turkish Maritime Pilots' Association at 23 October 2015, Hilton Hotel, Izmir.

In the opening ceremony, two distinguished keynote speakers have presented their presentations. Captain Stein Inge DAHN who is the president of European Maritime Pilots' Association(EMPA) has given a fulfilling speech on switching to hand steering by giving an example from the automation in the Aviation Industry. The second keynote speaker Robert G. Allan, who is the Executive Chairman of Robert Allan Ltd., has given a leading speech under the title of "The State of the Art in Escort Tug Technology -2015".

Five key points have come into prominence during the symposium. To summarize:

- $\quad$ To prevent ships and cargos which are exposed to damages,

- To prevent marine and coastal environments against pollution due to collisions,

- $\quad$ To establish fast, secure and well organized sea traffic

- $\quad$ To develop new escort tug technologies and pilotage softwares in the national level which is open to competitions in the international markets.

- $\quad$ Opening maritime pilotage into the competitions in the areas which needs special expertize.

In my opinion, the topics discussed in the symposium have the attendants won a wide horizon in the field. However, the presentations related to Escort Tug Technologies were insufficient from the standpoint of both quality and numbers of the manuscripts presented.

Due to importance of Maritime Pilotage/Towage Services and Technologies, much more attentions must be taken in the national and international levels and sustainability of the symposium must be provided. 